\title{
The Way-Finding in Educational Modular Buildings: The Case of the Male Engineering Building at Qatar University
}

\author{
Simona Azzali $\mathbb{D}^{1}$ and Eman Abdel Sabour ${ }^{2}$ \\ ${ }^{1}$ Department of Architecture, School of Design and Environment, National University of Singapore (NUS), 4 Architecture Drive, \\ Singapore 117566 \\ ${ }^{2}$ Department of Architecture and Urban Planning, College of Engineering, Qatar University, P.O. Box 2713, Doha, Qatar
}

Correspondence should be addressed to Simona Azzali; simona.azzali@yahoo.com

Received 6 August 2017; Revised 12 January 2018; Accepted 11 February 2018; Published 15 April 2018

Academic Editor: Pier Paolo Rossi

Copyright (c) 2018 Simona Azzali and Eman Abdel Sabour. This is an open access article distributed under the Creative Commons Attribution License, which permits unrestricted use, distribution, and reproduction in any medium, provided the original work is properly cited.

\begin{abstract}
Way-finding is the ability of people to perceive routes, flow patterns, or passageways inside and/or around a building. In other words, it is the capability of a person to know their whereabouts in a space. Modular buildings and complex spatial plan structure, in general, can be very confusing, especially from a way-finding point of view. This research attempts to measure the way-finding performance of a modular building by assessing the users' experience in finding their way inside the Male Engineering Building at Qatar University. The study involved students, faculty, and staff members that utilize that space daily. The research focused on accessing indoor spaces as well as the walkways and spaces connected to the building. Results show that parameters as the use of colours and numbers can improve capability and swiftness in way-finding. In future research, several types of signage and visual elements will be tested, in order to understand how they can enhance way-finding efficiency and user performance within indoor spaces.
\end{abstract}

\section{Introduction}

The aim of this research is to assess the way-finding performance and the ability of people to orient them in a modular construction by analysing the case of Male Engineering Building at Qatar University. But firstly, some definitions are needed. In the architecture field, a module is one of a set of parts that can be connected or combined to build or complete something; in other words, it can be considered as the size of some part taken as a unit of measure by which the proportions of an architectural composition are regulated [1]. One can define a modular building as any system composed of separate components that can be connected together. Usually, these components are similar units or subcomponents, which are combined repeatedly to create a total system. In modular buildings, it is usually possible to replace or add any one component (module) without affecting the rest of the system. The opposite of a modular is an integrated, or organic, building, in which no clear divisions exist between components.

Many authors [2-8] have studied way-finding, but only little attention has been given to way-finding in educational buildings. Within this context, the objective of the research is to measure the level of orientation inside the Male Engineering Building at Qatar University, by assessing the users' satisfaction in finding their way within the building. Our work evaluated whether it is necessary-and how-an improvement to its circulation. The research question that guided our study is the following: "What is the best technique for creating an efficient and effective way-finding in modular buildings?" And the aim of the researchers was to understand which parameters can influence the capability and rapidity in finding the way through a modular building. Are age and type of users (students, visitors, staff, and faculty) directly related to it? Is the frequency of use related to the ease of finding the way? Our hypothesis is that, by using visual elements (numbers, colours, letters, or other visual elements), way-finding in modular buildings will be improved. Indeed, signage is commonly employed to enhance way-finding efficiency, especially in buildings with complex floor plan configurations. Signage can have three conditions: no signage, textual signage, or graphical/visual signage [9], or a combination of the last two. 
We conducted a survey involving 54 people; most of them were students, staff, or faculty members from the College of Engineering that utilize the building daily. Data collection and analysis are presented in the next section of the research, while results are shown in the final section. Future research will test several types of signage to understand how they can enhance way-finding efficiency and performance.

\section{Case Study: The Male Engineering Building at QU}

Qatar University (QU) is the Qatar's national and major institution of higher education. It comprised seven colleges and composed of several buildings and outdoor spaces. QU is located on the northern side of Doha, approximately 16 kilometres from the city centre. QU's main campus is built on a total area of about 8 square kilometres, with architecture that is distinguished and modern, while reflecting the ideals of traditional Islamic design. The oldest section of the campus is the Male Engineering Building, erected in 1985 (Figure 1). The Egyptian architect Kamal el Kafrawi was responsible for the overall design and planning, whilst Ove Arup Partners were the consultants to undertake structural and engineering service design and site supervision $[10,11]$.

The space is a two-floor building composed of 10 corridors. The layout is based on a grid form: an octagon of $8.4 \mathrm{~m}$ in width and a square with sides of $3.5 \mathrm{~m}$. The octagons are adjacent and connected with squares to form the modular pattern. Each octagonal classroom module is linked to at least two "lobbies." One lobby can be used as either an entrance and a transition space between classrooms or an additional but secluded classroom space, and the second lobby can be used as a source of natural light and a meeting place (Figures 2 and 3). The octagonal units are surmounted by wind towers, which provide cool air and reduce humidity. Towers of light are also introduced and are intended to control the harsh sunlight, and abundant use of mashrabiyas and some stained glass also serve to mediate the environment. Open and partially covered courtyards, planted and often with fountains, are plentiful throughout the site. The architect puts a strong emphasis on natural ventilation, one of the many links in which he relates to the traditional architecture of the region [12]. According to the architect, the octagonal structure was used to give convenient support to the square wind towers and towers of light: the octagonal form minimizes heat absorption by shortening the period of time the sun shines on any given side. The wind towers are a substitute for mechanical ventilation and air-conditioning in case of power failure, and they also characterize the outline of the university buildings and relate to the cultural environment [13].

Qatar University has recently introduced a new code to classify its buildings on campus: one digit is given for the zones (A, B, and $\mathrm{C}$ ), two digits define the building, and other two are the floor and the last two digits for the room. For example, C 070149 means: zone C, building 07 (which corresponds to the Male Engineering Building), first floor (01), and room no. 49. This building, object of our analysis, is commonly known as "Corridors" because it is made of 10

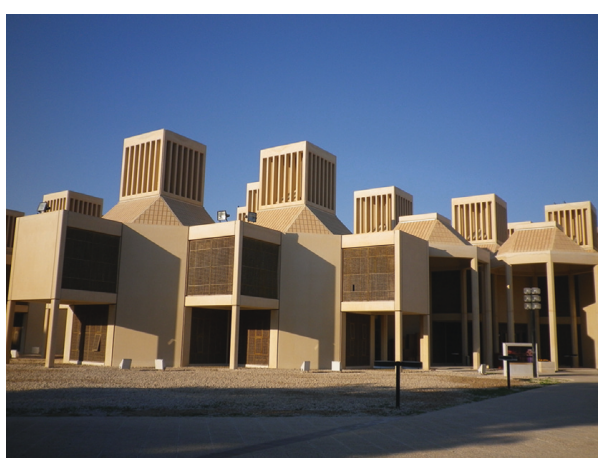

FIgure 1: The case study: the Male Engineering Building at Qatar University.

identical parallel corridors. In order to make way-finding easier, even if it is one single building, each part of it (each "corridor") is named by a letter (from A to J). Until two years ago, before the new building classification code was introduced, "corridors" were defined by numbers (from 1 to 10). This change in classifying the building is still making a vast part of the users confused.

Way-finding is the ability of people to perceive routes, traffic patterns, or passageways in and around a building. In other words, it is the capability of a person to know their whereabouts in a place. Some of the relevant aspects that can improve and contribute to a successful way-finding mechanism are sign design, signage system, and environmental graphics [12]. According to Carlson et al. [15] and Hölscher et al. [16], usually, people get lost in buildings because of three main contributing factors: the spatial structure of the building, the cognitive maps that users construct as they navigate, and the strategies and spatial abilities of the building users. Although it is generally recognized that the spatial structure of a building is an important factor in way-finding performance, poor research has been done to relate way-finding performance directly to topological and geometrical properties of spatial environments [17]. In this study, the authors collected data to measure the level of orientation in the Male Engineering Building at Qatar University by assessing the users' satisfaction in finding their way and analysing the main issues related to it. The authors provided empirical evidence that way-finding performance and the ability of people to orient themselves in their environment depend partly on the geometrical relations between different parts of the space. In future research, our work will evaluate how to improve the circulation in the building, by defining a framework made by immediate-, short-, and long-term recommendations. This study is specifically designed to ease way-finding and orientation in the Male Engineering Building at QU.

\section{Survey Distribution and Data Collection}

Data were collected through an online survey. The questionnaire was devised to assess the quality of the indoor spaces in the Male Engineering Building, and it was composed of 10 questions. It included attitudinal scales as well as a selection of options. The questionnaire was distributed online for three weeks, and 54 responses were collected. The survey aimed at 


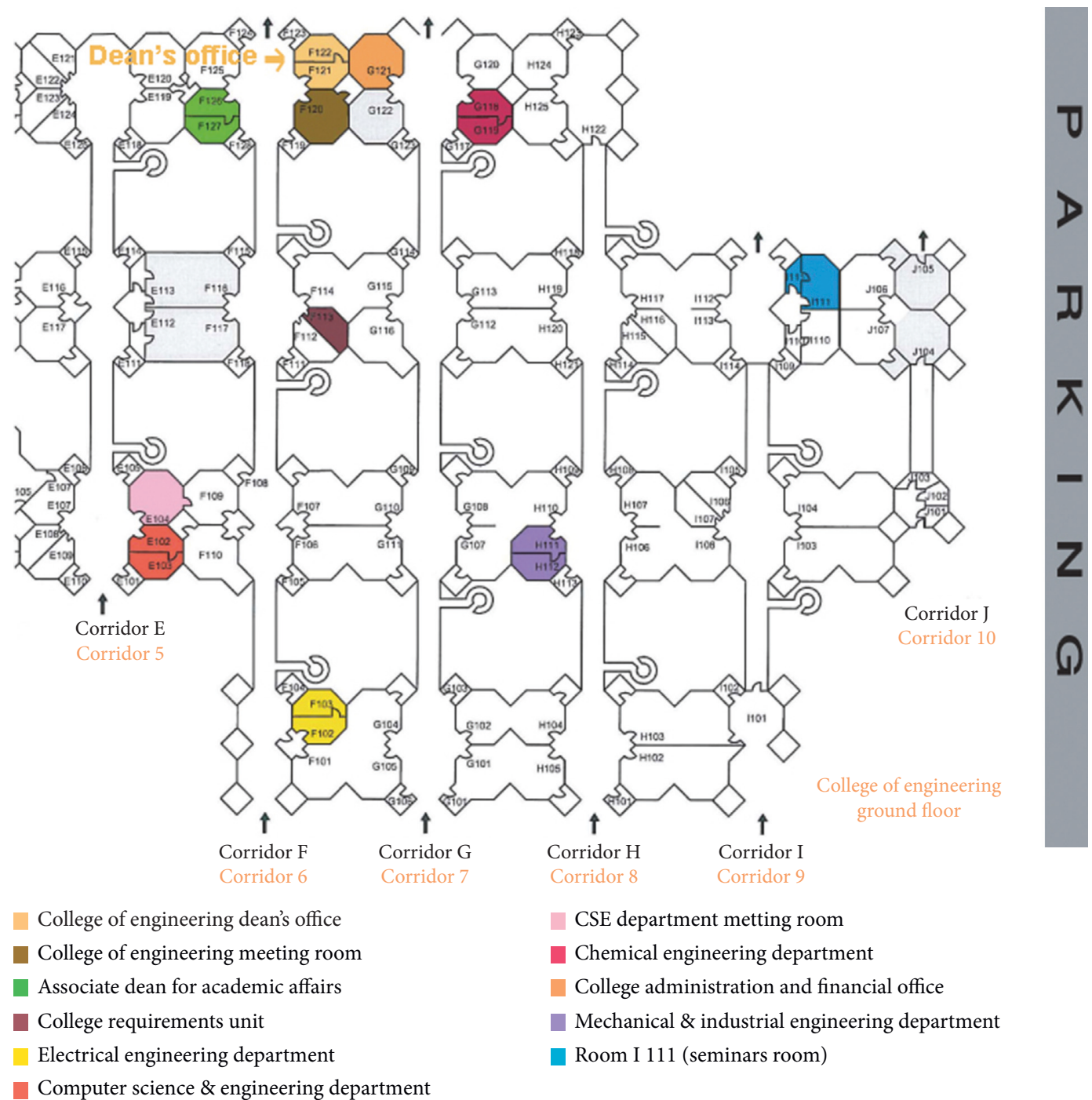

FIgure 2: Map of the Male Engineering Building at Qatar University [14].

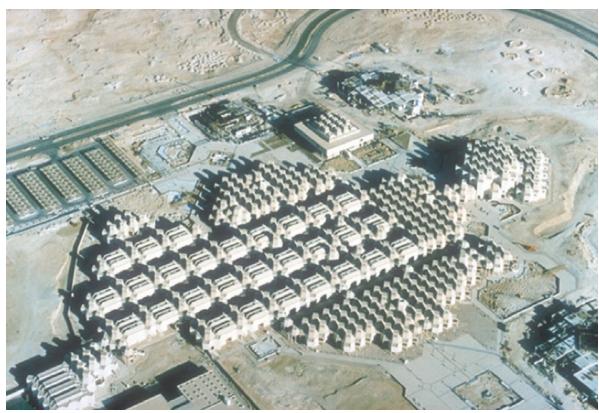

FIgURE 3: Aerial view of Qatar University campus: early stages of implementation.

rating the issues in way-finding according to users' experience in the campus. Respondents were requested to focus on the indoor spaces of the building, as well as the walkways and spaces connecting to it. Participating students and staff members were randomly selected (details in Table 1). Another round of questionnaire distribution will be undertaken in the
TABle 1: Descriptive statistics of respondents to the questionnaire.

\begin{tabular}{lcc}
\hline & Men & Women \\
\hline Students & 12 & 10 \\
Staff and faculty & 14 & 12 \\
Visitors & 4 & 2 \\
Total & 30 & 24 \\
\hline
\end{tabular}

second stage of the research. The full questionnaire is available online [18].

\section{Data Analysis and Results}

In the following section, an analysis of the results is presented. According to the survey, the user's sample found difficult to find their destination especially the first time they visited the building: for $39.22 \%$, it was extremely difficult, and the same percentage (39.22\%) found it difficult. Only a 3.92\% (two persons) found it easy, while for no one was extremely easy. The situation changes when people get used to the building. 
In the third question, it was asked to rate how easy it is to find their destination after the first visit: only for $3.92 \%$, it is still extremely difficult, while for $13.73 \%$, it is extremely easy, and for $31.37 \%$ is easy. For $29.41 \%$, it is neither difficult nor easy to orient, while there is still a $21.57 \%$ of users who find difficult to find his/her way (Figures 4 and 5).

Q2. Using any number from 1 to 5 , where 1 is extremely difficult and 5 is extremely easy, what number would you use to rate how easy it was for you to find your destination, THE FIRST TIME?

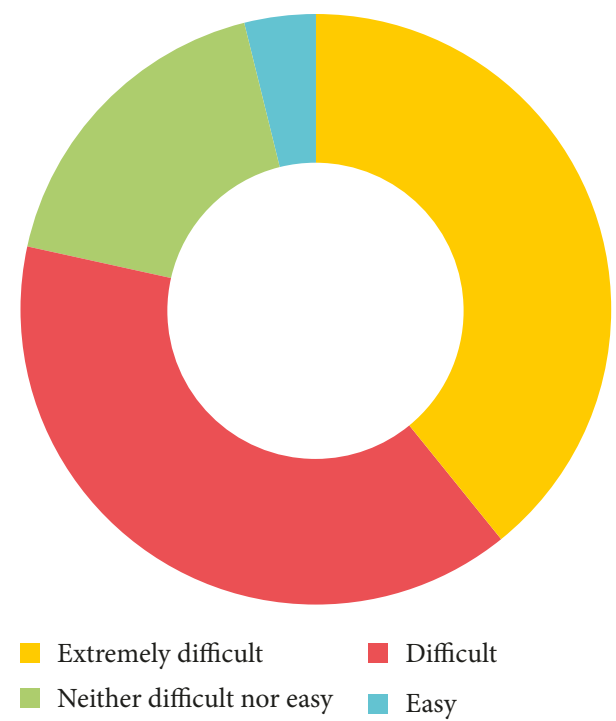

FIGURE 4: Visual representation of percentages of responses in Question 2.

Q3. Using any number from 1 to 5 , where 1 is extremely difficult and 5 is extremely easy, what number would you use to rate how easy it is AFTER THE FIRST TIME for you to find your destination in the Male Engineering Building?

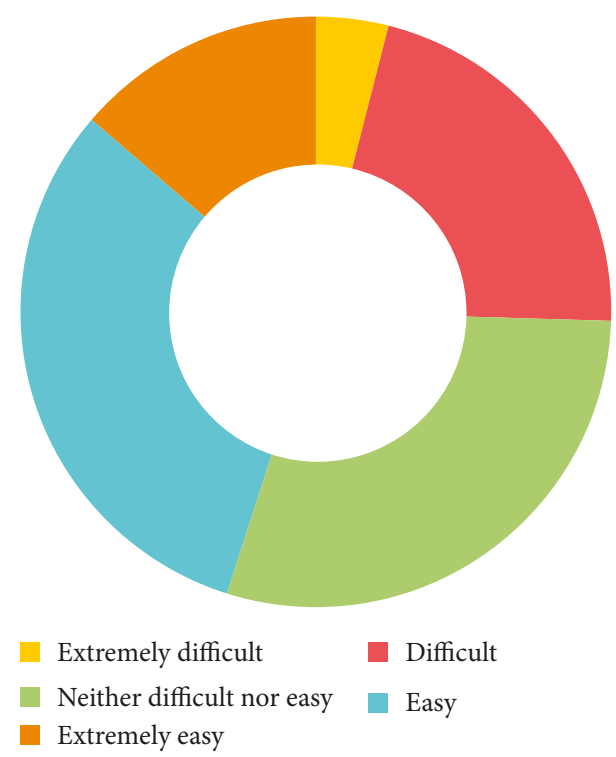

FIGURE 5: Visual representations of percentages of responses in Question 3.
4.1. Effect of Age on Way-Finding. To test whether the age of a participant in the survey affects the degree of relative ease in which he/she finds her/his way in the engineering compound, we performed Pearson correlation coefficient test. It is worth noting that since Pearson correlation coefficient requires the two variables to be stochastic (i.e., numerical), question 2 had to be modified to represent a number. The value of this number ranges from 1 to 5 . The value of the Pearson correlation coefficient we got was 0.2094289 . With a confidence interval of $90 \%$, we can say that the Pearson correlation coefficient ranges from -0.02734581 to 0.4239522 . The Pearson correlation coefficient indicates that there exists no relationship between age and the relative ease with which someone can find his/her way.

4.2. Effect of Gender on Way-Finding. Since the engineering building under study is the male's engineering building, it was necessary to test the hypothesis that men were more likely to find their place around the campus than women. For this test, we choose the question that asked the participants about their stance on the engineering building at present as opposed to the first time they used the building. The null hypothesis was that there is no difference between men and women regarding the relative ease with which they can find their way around. The alternative hypothesis is that there is a difference.

Equation (1) gives the null hypothesis:

$$
\text { the null hypothesis } \mathrm{H}_{0}: \mu_{\mathrm{M}}-\mu_{\mathrm{F}}=0 \text {, }
$$

the alternative hypothesis $\mathrm{H}_{1}: \mu_{\mathrm{M}}-\mu_{\mathrm{F}} \neq 0$.

The significance level we chose is $\alpha=10 \%$.

The $p$ value obtained is 0.04036 , which is significant. As such we reject the null hypothesis and accept the alternative hypothesis. As expected, since men are expected to access more the Male Engineering Building, they end in being more familiar with it.

4.3. Relationship between Number of Semesters Spent in the College and Way-Finding. We also wanted to investigate if there was a relationship between the number of semesters spent in the college and the degree of relative ease by which someone finds his/her way around the building. For this matter, we conducted a bivariate linear regression model, with the response variable being the relative ease with which someone finds his/her way around the college and the independent variable to be the semesters spent in the college.

4.3.1. Correlation Check. Before performing a bivariate linear regression analysis, we performed a Pearson correlation coefficient test to determine if there was a relationship between the two variables. The Pearson correlation coefficient we found was 0.4017439. Applying a confidence interval of $90 \%$, we get the range of the Pearson correlation coefficient to be 0.5821134 to 0.1836913 . There seems to be a positive linear relationship between the two variables. So, to further validate our results, we performed the bivariate linear regression. 


$$
\begin{aligned}
& \text { Call: } \\
& \operatorname{lm}(\text { formula }=\text { file[, "q3"] file[, "time”]) } \\
& \text { Residuals: } \\
& \text { Min 1Q Median 3Q Max } \\
& \begin{array}{lllll}
-2.2743 & -0.7672 & 0.2187 & 0.3971 & 2.0544
\end{array} \\
& \begin{array}{lcrrc} 
& \text { Estimate Std. } & \text { Error } & \mathrm{t} \text { value } & \operatorname{Pr}(>|\mathrm{t}|) \\
\text { (Intercept) } & 2.61696 & 0.27674 & 9.456 & 1.53 \mathrm{e}-12^{* * *} \\
\text { file[, "time"] } & 0.16433 & 0.05407 & 3.039 & 0.00383^{* *}
\end{array} \\
& \text { Signif. codes: } 0^{(* * *)} 0.0011^{(* *)} 0.011^{(*)} 0.05 \text { ‘ } 0.1 \text { ' } 1
\end{aligned}
$$

\begin{tabular}{|c|c|c|c|c|}
\hline \multicolumn{5}{|c|}{$\begin{array}{l}\text { > TukeyHSD(anova_result) } \\
\text { Tukey multiple comparisons of means } \\
\quad 95 \% \text { family-wise confidence level }\end{array}$} \\
\hline \multicolumn{5}{|c|}{ Fit: aov(formula = file[, "q3"] file[, "type"]) } \\
\hline \multicolumn{5}{|l|}{ \$ 'file[, "type"]' } \\
\hline & diff & lwr & upr & $\mathrm{p}$ adj \\
\hline Staff-Faculty & 0.5000000 & -0.62200444 & 1.6220044 & 0.7128044 \\
\hline Student-Faculty & 0.1250000 & -0.99700444 & 1.2470044 & 0.9977411 \\
\hline Student and staff-Faculty & 1.2857143 & -0.08593579 & 2.6573644 & 0.0758091 \\
\hline Visitor-Faculty & -2.0000000 & -4.91920258 & 0.9192026 & 0.3084060 \\
\hline Student-Staff & -0.3750000 & -1.35906299 & 0.6090630 & 0.8143701 \\
\hline Student and staff-Staff & 0.7857143 & -0.47559850 & 2.0470271 & 0.4032642 \\
\hline Visitor-Staff & -2.5000000 & -5.36901198 & 0.3690120 & 0.1143940 \\
\hline Student and staff-Student & 1.1607143 & -0.10059850 & 2.4220271 & 0.0845748 \\
\hline Visitor-Student & -2.1250000 & -4.99401198 & 0.7440120 & 0.2360332 \\
\hline Visitor-Student and staff & -3.2857143 & -6.26124108 & -0.3101875 & 0.0238107 \\
\hline
\end{tabular}

Box 1: Regression Model.

Box 2: TukeyHSD function.

4.3.2. Linear Relationship between Semesters Spent in the College and Way-Finding. Applying the regression model, we get the results in Box 1 .

Both the intercept and the slope term have very low " $p$ " values, indicating that both terms are significant. Thus, we can conclude that there exists a relationship between time spent in the university and the level of familiarity with the Male Engineering Building and that this relationship is linear. According to the regression results, a person starts with a "2.61696" level of familiarity with the campus (which corresponds to neither satisfied nor dissatisfied) and keeps increasing the familiarity with the campus by " 0.16433 " points with each passing semester.

4.4. Effect of Different Groups on Way-Finding. The next area of concern involved the ANOVA. We wanted to study the effect of whether being a student, staff, or academic member on the relative ease with which one finds his/her place around the building. An ANOVA was applied.

4.4.1. Effect of Different Groups on Way-Finding without Taking into Consideration the Time Spent in the College. An initial finding by applying the ANOVA analysis is that there is a difference in response between the groups that responded to the survey. We applied the TukeyHSD function to get more details (Box 2).

From this plot, we realized that the biggest difference between groups is between "visitors" and "students and staff members." In addition, we also noted that another major difference between means occurs also between "visitors" and "other groups." It is worth noting that this statistic might not be very accurate because we had a very little number of "visitors" in our survey; thus, this test must be applied again (Box 3). 


$$
\begin{array}{lrrrrr}
\text { > summary(anova_result) } & & & \\
& \text { Df } & \text { Sum Sq } & \text { Mean Sq } & \text { F value } & \operatorname{Pr}(>\mathrm{F}) \\
\text { file[, "type"] } & 3 & 8.45 & 2.8180 & 2.937 & 0.0433 \text { * } \\
\text { Residuals } & 45 & 43.18 & 0.9595 & & \\
--- & & & & & \\
\text { Signif. codes: } & 0^{\text {(***) }} 0.0011^{\text {(**) }} 0.01 \text { '*’ } 0.05 \text { '? } 0.1 \text { ' ' } 1
\end{array}
$$

\begin{tabular}{|c|c|c|c|c|}
\hline \multicolumn{5}{|c|}{$\begin{array}{l}\text { > TukeyHSD(anova_result) } \\
\text { Tukey multiple comparisons of means } \\
\quad 95 \% \text { family-wise confidence level } \\
\text { Fit: aov(formula = file[, "q3"] file[, "type"]) } \\
\text { \$ 'file[, "type"]' }\end{array}$} \\
\hline & diff & lwr & upr & $\mathrm{p}$ adj \\
\hline Staff-Faculty & 0.5000000 & -0.553395513 & 1.553396 & 0.5887825 \\
\hline Student-Faculty & 0.1250000 & -0.928395513 & 1.178396 & 0.9888702 \\
\hline Student and staff-Faculty & 1.2857143 & -0.002061403 & 2.573490 & 0.0505061 \\
\hline Student-Staff & -0.3750000 & -1.298888982 & 0.548889 & 0.7016969 \\
\hline Student and staff-Staff & 0.7857143 & -0.398471075 & 1.969900 & 0.3009122 \\
\hline Student and staff-Student & 1.1607143 & -0.023471075 & 2.344900 & 0.0565885 \\
\hline
\end{tabular}

Box 3: Reapplication ox the ANOVA analysis.

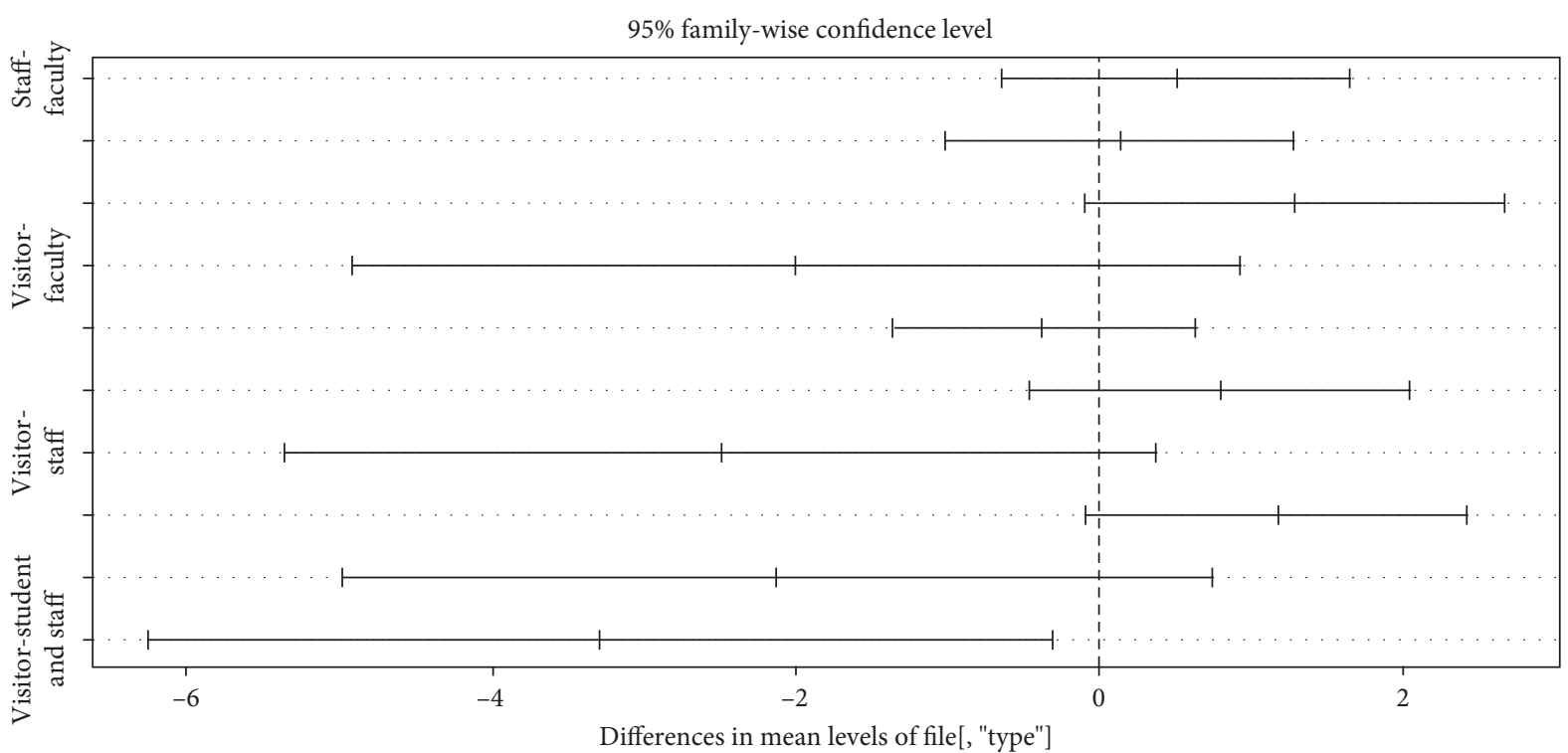

FIGURE 6: Differences of means between groups plot.

Box 4: TukeyHSD function.

As we can see from the reapplied ANOVA test, the significance level gained from the previous test. This was expected since the group "visitors" which was removed for this ANOVA test could have been considered an anomaly or an extremity and that is why we had the huge difference of means between the "visitors" group and the rest of the other groups.

As we can see from the results in Figure 6, the difference between the means of the groups that participated in the survey is less than before; however, we still do have a difference between the means. The biggest disparity between groups was between "student and staff" and "faculty." To better visualize this, we plotted the TukeyHSD function (Box 4), represented in Figure 7.

4.4.2. Effect of Different Groups on Way-Finding Taking into Consideration Time Spent in the College. We further refined 


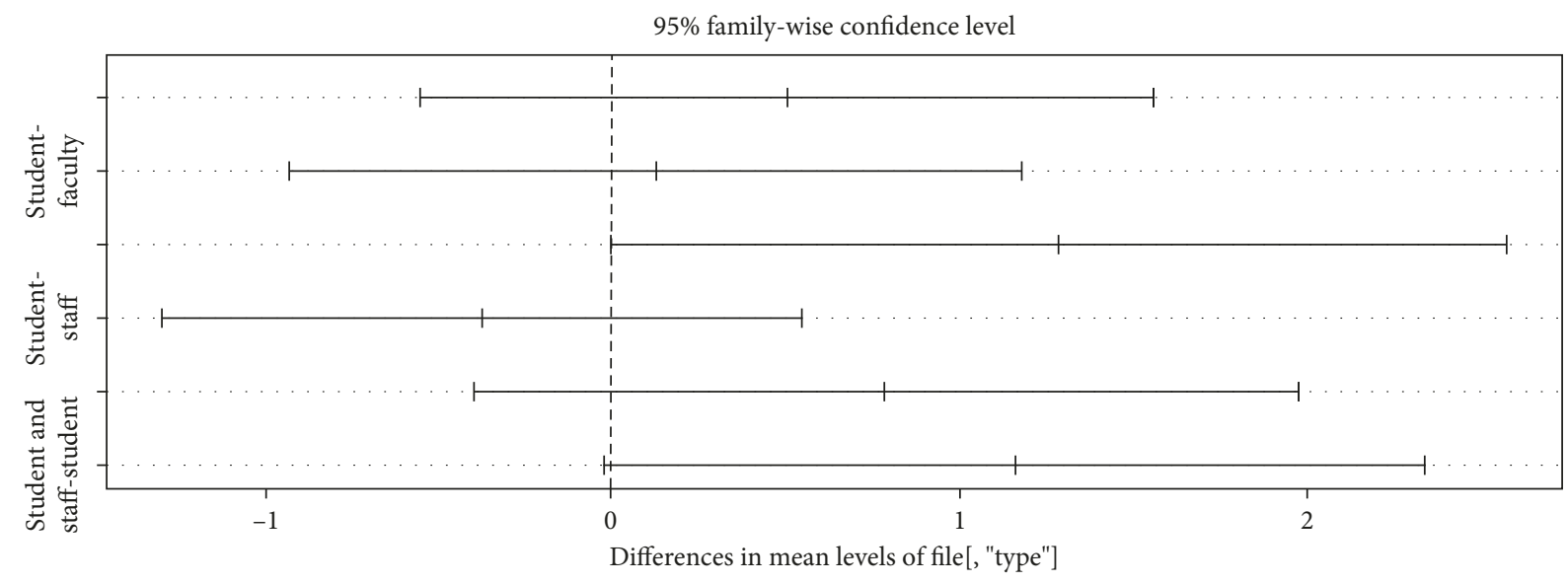

Figure 7: Difference of means between different groups plot.

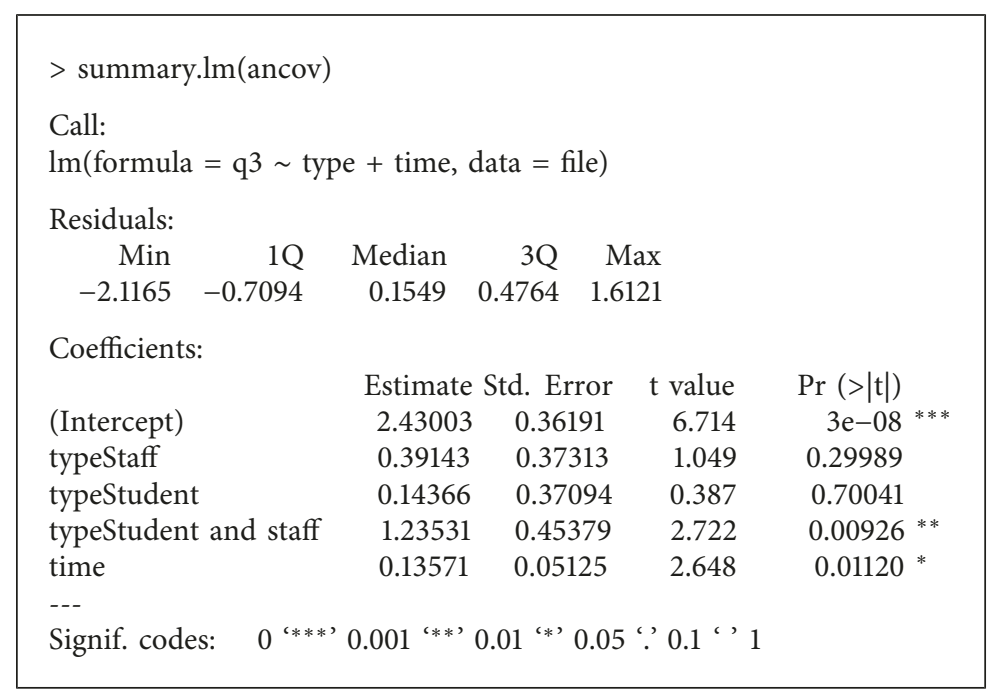

Box 5: ANCOVA analysis.

the ANOVA analysis we performed above by taking into consideration the covariate "time spent in the university." It was clear from the regression analysis that as time spent in the university increases the level of relative ease by which one finds his/her way around the campus increases. However, we further increased the precession of our estimate by studying the effect of the time spent in the university on the different groups. It is worth noting that the "visitors" group was discarded from this test because it is not applicable in this context. Applying the ANCOVA analysis, we get the result shown in Box 5.

From the results above, we can conclude that the group "student and staff" shows the most significant increase with time. In addition, this group has also the most significant $p$ value between the other groups. It is also worth noting that the covariate "time" has a significant $p$ value, which means that the degree of relative ease with which one finds her/his way around the college really does get better with time.
4.5. Effect of Semesters Spent in the College on Way-Finding (Binary Logistic Model). Binary logistic regression requires the response variable to be dichotomous (Yes/No), and the sample was chosen to be sufficiently large (more than 50). In our survey, we asked a question "Are you satisfied with the ...," where the response to this question was yes, no, and neither. Few people responded with neither, so we discarded those who did, for the purpose of this regression model. We then applied this regression model using the independent variable as the number of semesters spent in the university. Why did we perform this model when we already applied the linear regression model? Because many people cannot accurately quantify their feelings. The second question asked the participants to rate their feelings as a number from 1 to 5 . However, some people might give data that might disturb or give wrong statistical inferences about the question asked. That is why we added a question in the survey that asks the participant to answer with a yes or no, if he is satisfied or not with the current system. Applying the binary logistic model, we get the result shown in Box 6 . 


$$
\begin{aligned}
& >\text { summary(bonary.model) } \\
& \text { Call: } \\
& \operatorname{glm}(\text { formula }=\text { response } \sim \text { time, fanily }=\text { "binomial", data }=\text { file }) \\
& \text { Deviance Residuals: } \\
& \begin{array}{llll}
\text { Min } & \text { 1Q Median } & \text { Max }
\end{array} \\
& \begin{array}{lllll}
-1.8603 & -0.9422 & 0.6460 & 0.8613 & 0.9153
\end{array}
\end{aligned}
$$

$\begin{array}{lcrrr} & \text { Estimate Std. } & \text { Error } & \mathrm{z} \text { value } & \operatorname{Pr}(>|\mathrm{z}|) \\ \text { (Intercept) } & 1.6824 & 0.7947 & 2.117 & 0.0343 \\ \text { time } & -0.1470 & 0.1501 & -0.979 & 0.3276\end{array}$ *

Signif. codes: 0 (***) $0.001^{(* *)} 0.01$ (*) 0.05 ‘ 0.1 “' 1

(Dispersion parameter for binomial family taken to be 1)

Null deviance: 43.801 on 37 degrees of freedom Residual deviance: 42.803 on 36 degrees of freedom AIC: 46.803

Number of Fisher Scoring iterations: 4

Box 6: Application of the binary logistic model.

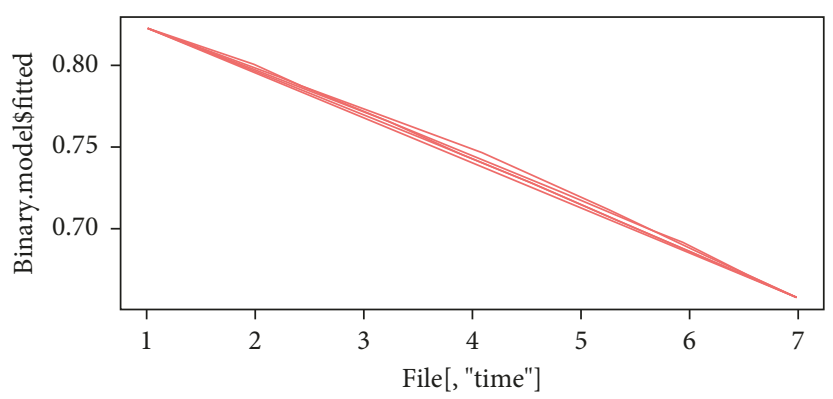

FIgURe 8: Plot of the probability model.

Q 10 in your opinion, which is the best way to define corridor circulation?

(1) Also it could be mix of colours and numbers as visualization is easiar to recall.

(2) All of them.

(3) Colour and number written in different colour.

(4) The logic of the building has to be explained to students. The logic is simple.

(5) Letter and number combination.

(6) Please use sign boards.

(7) Colours and letters.

(8) Letters combined with numbers.

(9) Number and colour together.

(10) Hhh! i did not read this before answering 9 you have gave colour option.

(11) I guess both numbers and colours are good to define the building.

(12) Maps with "you are here."

(13) Signs and maps (preferably signs on the floor as it is the easiest for example).

Figure 9: Comments on Q10: 13 responses.

Figure 8 represents the plot of binary logistic model.

By analysing Figure 8, it can be concluded that as time increases, the possibility of being dissatisfied decreases.
Finally, according to the responses to Question 10 (Figures 9 and 10), users believe that colours and numbers can help in defining way-finding and circulation. 


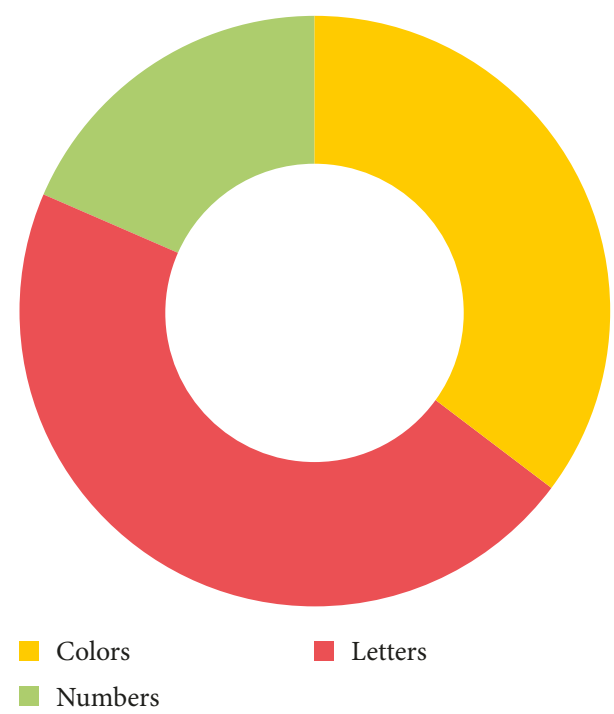

FIGURE 10: Visual representations of percentages of responses in Question 10.

\section{Conclusions}

Complex spatial plan structures can be very confusing, especially from a way-finding point of view. This is particularly true for modular buildings, as the way-finding of these buildings stems largely from the high degree of similarity between the modules and thus a lack of architectural differentiation in terms of Weisman [8]. Although in modular buildings, from a plan view, the spatial logic and layout configuration can be understood quite well, building users experience way-finding from a personal perspective that does not reveal this structure readily. Within this context, the objective of this research was to measure the level of orientation and the quality of the indoor spaces in the Male Engineering Building at Qatar University, by assessing users' satisfaction in finding their way in the building. The assessment was done by delivering a questionnaire composed of 10 questions. It included attitudinal scales as well as a selection of options. The survey evaluation aimed at rating the issues in way-finding according to the experience of the campus. The people enrolled were requested to focus only on the indoor of the Male Engineering Building of Qatar University, as well as the walkways and spaces connecting the building. Participants were randomly selected. Detailed results were presented in the previous sections. The samples found difficult to find their destination especially the first time they visited the building, while way-finding increases with the use of it. The results show that there are no relations between age and the relative ease with which someone can find his/her way, while men were found to be more familiar with the campus. Also, we investigated the relationship between semesters spent in the college and the degree of relative ease by which someone finds his/her way around the college. The study confirmed that there exists a relationship between time spent in the university and the level of familiarity with the engineering campus, and that this relationship is linear. Finally, according to our research, users confirmed that colours and numbers could help in defining way-finding and circulation. As part of our future research, we will test several types of signage and visual elements (numbers, colours, and letters) to understand how they can enhance way-finding efficiency and performance and to understand what the best technique for creating an efficient and effective way-finding in modular buildings is.

\subsection{Future Research.}

(1) An improved evaluation of the indoor way-finding in the building, by adding several methods of investigation, as direct observation, walkthrough evaluation, extended survey questionnaire, and behavioural mapping studies of key spaces. A multilayered methodology will allow developing more reliable results.

(2) An extension of the analysis of the quality of wayfinding to the outdoor space.

(3) The design of a framework for improving the indoor/outdoor space quality in the Male Engineering Building of Qatar University, by defining a list of immediate actions, short-term actions, and long-term actions.

\section{Conflicts of Interest}

The authors declare that there are no conflicts of interest regarding the publication of this paper.

\section{Acknowledgments}

This research was made possible by GSRA Grants nos GSRA1-1-1119-13007 and GSRA1-1-1119-13006 from the Qatar National Research Fund (a member of Qatar Foundation). The findings achieved herein are solely the responsibility of the authors. The authors also wish to express their gratitude to Dr. Andrei Sleptchenko for his help, assistance, support, and guidance.

\section{References}

[1] Oxford Dictionaries, Way-Finding, https://en.oxforddictionaries. com/definition/wayfinding.

[2] A. W. Agrawal, M. Schlossberg, and K. Irvin, "How far, by which route and why? A spatial analysis of pedestrian preference," Journal of Urban Design, vol. 13, no. 1, pp. 81-98, 2008.

[3] D. L. Butler, A. L. Acquino, A. A. Hissong, and P. A. Scott, "Wayfinding by newcomers in a complex building," Human Factors: The Journal of the Human Factors and Ergonomics Society, vol. 35, no. 1, pp. 159-173, 1993.

[4] R. Ewing and S. Handy, "Measuring the unmeasurable: urban design qualities related to walkability," Journal of Urban Design, vol. 14, no. 1, pp. 65-84, 2009.

[5] R. H. Lo, "Walkability: what is it?," Journal of Urbanism, vol. 2, no. 2, pp. 145-166, 2009.

[6] V. Mehta, "Walkable streets: pedestrian behavior, perceptions and attitudes," Journal of Urbanism, vol. 1, no. 3, pp. 217-245, 2008 . 
[7] R. Passini, "Wayfinding design: logic, application and some thoughts on universality," Design Studies, vol. 17, no. 3, pp. 319-331, 1996.

[8] J. Weisman, "Evaluating architectural legibility way-finding in the built environment," Environment and Behavior, vol. 13, no. 2, pp. 189-204, 1981.

[9] M. J. O'neill, "Effects of signage and floor plan configuration on wayfinding accuracy," Environment and Behavior, vol. 23, no. 5, pp. 553-574, 1991.

[10] Qu.edu.qa. (n.a), Qatar University, http://www.qu.edu.qa/.

[11] J. Lockerbie, Planning in Qatar 01, 2013, http://catnaps. org/islamic/planning.html.

[12] A. M. Salama, "When good design intentions do not meet users expectations: exploring Qatar University campus outdoor spaces," International Journal of Architectural Research, vol. 2, no. 2, pp. 57-77, 2008.

[13] K. El Kafrawi, One Image, 1993, https://archnet.org/library/ images/one-image.jsp?location_id=1786\&image_id=58048.

[14] Faculty.qu.edu.qa (n.a), Mazen Omar Hasna, Office Map, Qatar University, http://faculty.qu.edu.qa/hasna/map.aspx.

[15] L. A. Carlson, C. Hölscher, T. F. Shipley, and R. C. Dalton, "Getting lost in buildings," Current Directions in Psychological Science, vol. 19, no. 5, pp. 284-289, 2010.

[16] C. Hölscher, S. J. Buchner, T. Meilinger, and G. Strube, "Adaptivity of wayfinding strategies in a multi-building ensemble: the effects of spatial structure, task requirements, and metric information," Journal of Environmental Psychology, vol. 29, no. 2, pp. 208-219, 2009.

[17] S. Werner and L. E. Schindler, "The role of spatial reference frames in architecture: misalignment impairs way-finding performance," Environment and Behavior, vol. 36, no. 4, pp. 461-482, 2004.

[18] Surveymonkey.com (n.a), Wayfinding in Modular Buildings Survey, https://www.surveymonkey.com/s/RDPXZGW. 


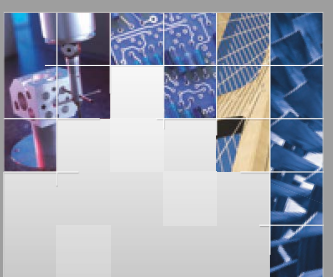

\section{Enfincering}
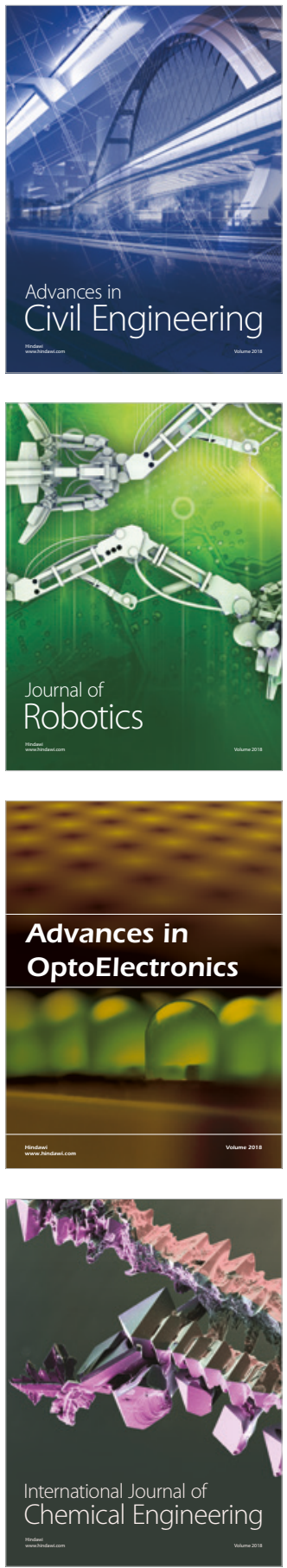

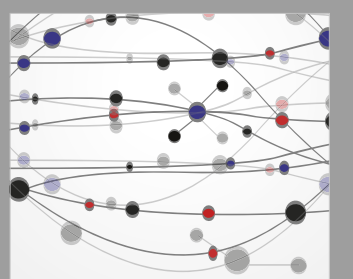

\section{Rotating \\ Machinery}

The Scientific World Journal

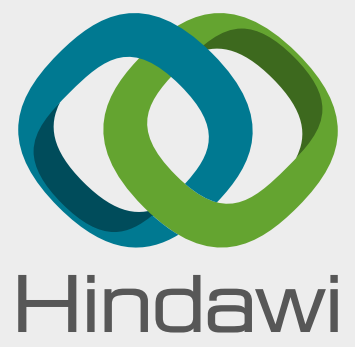

Submit your manuscripts at

www.hindawi.com
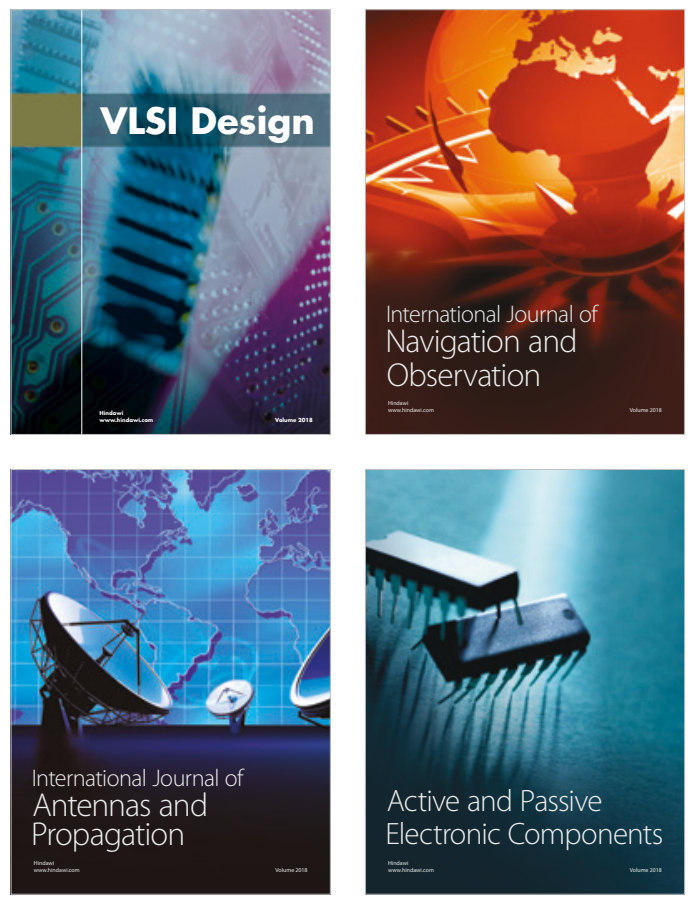
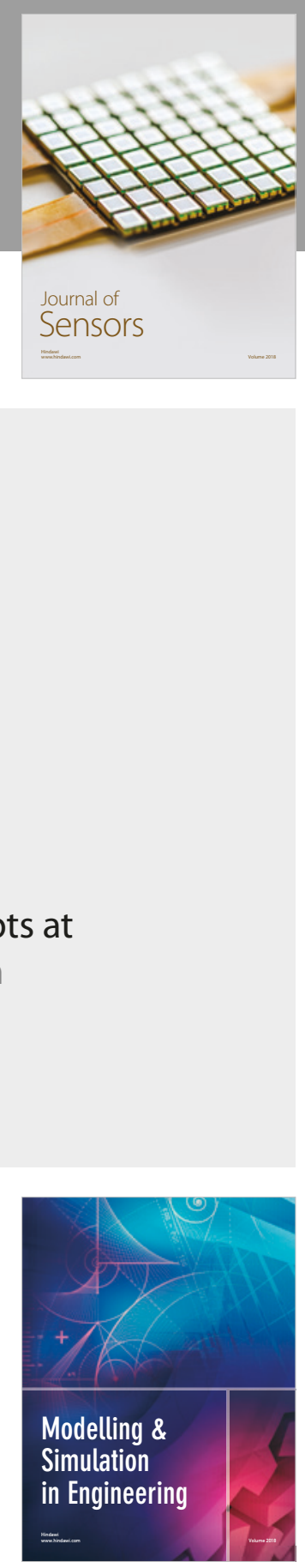

\section{Advances \\ Multimedia}
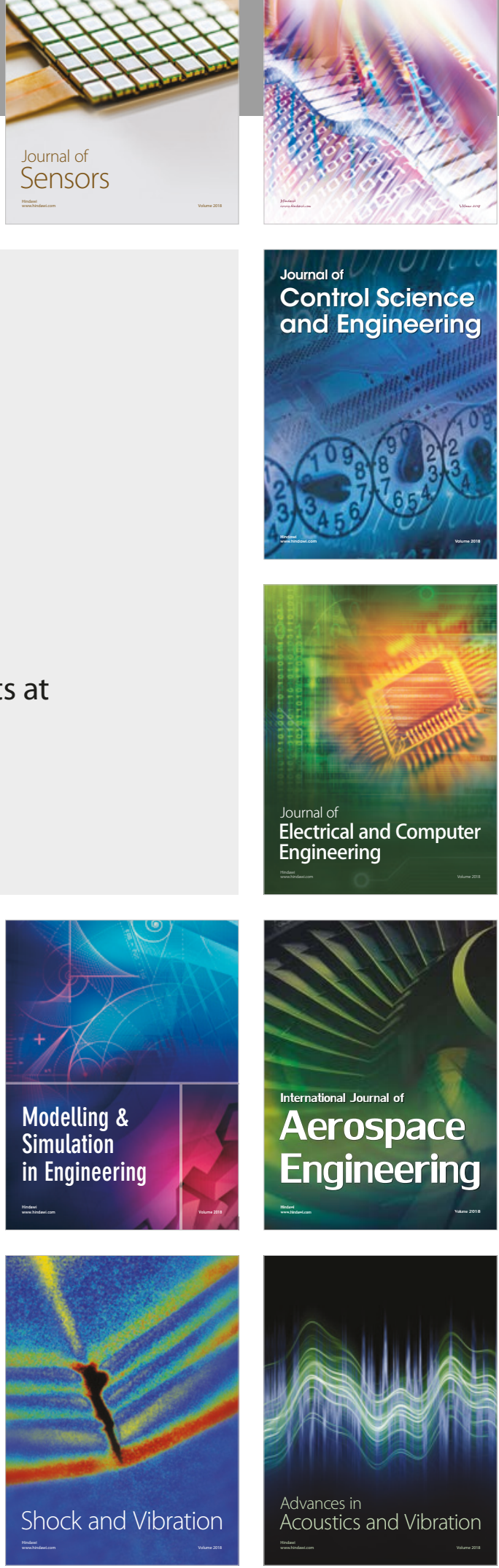